\title{
DINAMICAS TERRITORIALES EN EL NOROESTE DE LA PENÍNSULA IBÉRICA: CASTILLA Y LEÓN Y SU RELACIÓN CON LA EURORREGIÓN GALICIA-NORTE DE PORTUGAL
}

\author{
Rubén Camilo LOIS GONZÁLEZ - Miguel PAZOS OTÓN - María José \\ PIÑEIRA MANTIÑÁN \\ Departamento de Geografía -Universidad de Santiago de Compostela
}

Recibido: 01/04/2010

Aceptado: 03/05/2010

RESUMEN: El Noroeste de la Península Ibérica es un espacio geográfico complejo. A lo largo de los siglos, la rígida frontera entre España y Portugal fragmentó el espacio y frenó los intercambios de todo tipo (económicos, sociales, culturales). Sin embargo, el ingreso de los dos países ibéricos en la Unión Europea definió un nuevo escenario, en el que Galicia, Castilla y León y el Norte de Portugal interactúan entre sí, si bien lo hacen de manera desigual. En este trabajo se analizan las dinámicas territoriales que se establacen entre la Eurorregión Galicia-Norte de Portugal y Castilla y León, en un espacio geográfico caracterizado por su diversidad y su falta de homogeneidad.

PALABRAS CLAVE: Noroeste de la Península Ibérica, Eurorregión Galicia-Norte de Portugal, Castilla y León, dinámicas territoriales.

TERRITORIAL DYNAMICS IN THE NORTHWEST OF THE IBERIAN PENINSULA: CASTILE AND LEON AND EUROREGION GALICIA-NORTH PORTUGAL

ABSTRACT: The Northwest of the Iberian Peninsula is a complex geographic space. Throughout the centuries, the rigid border between Spain and Portugal fragmented the space and stopped the trading of all kinds (economic, social, cultural). However, the entrance of the two Iberian countries in the European Union set a new scenario, in which Galicia, Castile and Leon and the north of Portugal interact with each other, although they do so unevenly. In this paper we analyze the territorial dynamics between Galicia-North Portugal and Castile and Leon, in a geographical area characterized by its diversity and lack of homogeneity.

KEY WORDS: Northwest of the Iberian Peninsula, Euroregion Galicia-North Portugal, Castile and Leon, territorial dynamics.

DYNAMIQUES TERRITORIALES AU NORD-EST DE LA PENINSULE IBERIQUE: CASTILLE-ET-LEON ET SA RELATION AVECL'EUROREGION GALICE-NORD DU PORTUGAL

$\boldsymbol{R} \boldsymbol{E} \boldsymbol{S} \boldsymbol{U} \boldsymbol{M E}:$ Le Nord-Ouest de la Péninsule Ibérique est un espace géographique complexe. Tout au long des siècles, la frontière rigide entre l'Espagne et le Portugal espace fragmenté et a arrêté les échanges de toutes sortes (économiques, sociales, culturelles). Toutefois, le revenu des 
les deux pays ibériques dans l'Union européenne a fixé un nouveau scénario, dans lequel la Galice, Castille-et-Léon et le nord du Portugal interagissent les uns avec les autres, mais ils le font de manière inégale. Dans ce travail, la dynamique régionale qui establacen entre le Portugal et la Galice du Nord-Castille-et-Léon, dans une zone géographique caractérisée par sa diversité, et le manque d'homogénéité.

MOTS-CLÉS: Nord-est de la Péninsule Ibérique, Eurorégion Galice-Nord du Portugal, de Castille-et-Léon, dynamique territoriale.

DINAMMICAS TERRITORIAIS NO NOROESTE DA PENÍNSULA IBÉRICA: CASTELA E LEÃO EM LIGAÇÃO COM EUROREGIÃO GALIZA-NORTE PORTUGAL

RESUMO: O Noroeste da Península Ibérica é um espaço geográfico complexo. Ao longo dos séculos, a fronteira rígida entre Espanha e Portugal fragmentou o espaço e parou o comércio de todos os tipos (econômica, social, cultural). No entanto, o rendimento dos dois países ibéricos na União Europeia definiu um novo cenário, em que a Galiza, Castela e Leão e o norte de Portugal interagem uns com os outros, embora o façam de forma irregular. Neste trabalho analízase a dinâmica territorial entre a Galiza-Norte de Portugal e Castela e Leão, numa área geográfica caracterizada por sua diversidade e falta de homogeneidade.

PALAVRAS CHAVE: Noroeste da Península Ibérica, Euroregião Galiza-Norte Portugal, Castela e Leão, dinâmica territorial.

\section{INTRODUCCIÓN}

La Geografía como disciplina científica se ha encargado de demostrar, a lo largo de más de dos siglos, que el espacio no es isotrópico. Sin duda, el espacio y los procesos de territorialización constituyen variables explicativas de las dinámicas de desarrollo económico, de los niveles de vida de la población, de la especialización productiva de un determinado lugar o de las formas que adoptan las escenas y paisajes que durante todo el día nos encontramos frente a nosotros. Un espacio donde todas las afirmaciones de nuestra disciplina se cumplen perfectamente es el cuadrante Noroccidental de la Península Ibérica. Si por razones operativas de este artículo excluimos del mismo a Asturias y Cantabria, nos encontramos ante una realidad dividida entre dos Estados-nación clásicos en el mapa europeo, España y Portugal. Pero no sólo eso, la diferenciación y afirmación desigual de las Comunidades Autónomas españolas plantea el surgimiento de dos nuevos territorios de perfiles nítidos, Galicia y Castilla y León.

Por lo tanto, vamos a abordar la organización interna y las dinámicas territoriales de un área relativamente extensa donde el espacio es todo menos regular, uniforme y marcado por continuidades. Desde la perspectiva castellano-leonesa, la frontera con Portugal siempre estableció una separación evidente entre dos mundos culturales y lingüísticos distintos, y actuó dificultando los intercambios económicos y los contactos entre personas en una serie de comarcas rurales en declive, que lo que menos necesitaban era funcionar como confín de un territorio bastante aislado respecto al exterior (LÓPEZ TRIGAL, LOIS y GUICHARD, 
1997; LóPez Trigal y Guichard, 2000; Guichard, LÓPez Trigal y MARROU, 2000).

Las dificultades impuestas por la frontera internacional se han ido superando poco a poco, al mismo tiempo que la tradicional diferencia entre el mundo castellano o leonés y el gallego se ha traducido en la división autonómica de España mediante la aparición de dos Comunidades diferentes. Ambas, Galicia y Castilla y León, presentan semejanzas evidentes y han mantenido relaciones no interferidas a lo largo de los siglos, si bien sus lógicas individualizadas de desarrollo territorial, la aprobación de normas propias no exactamente coincidentes en urbanismo, ordenación del territorio y fomento de las obras públicas, educación, cultura, etc., han ido estableciendo matices en las estrategias internas y de relación con el exterior definidas por cada territorio. Por lo tanto, analizaremos las sinergias y discontinuidades de un ámbito supraregional constituido por tres realidades bien individualizadas, un marco de geografías dialécticas y cambiantes que gustamos de analizar en estos comienzos del siglo XXI.

En la presente contribución, empezaremos preguntándonos por la organización político-administrativa del Noroeste ibérico y, de manera especial, por las reconfiguraciones territoriales del mismo en periodos recientes. De hecho, el efecto de la frontera hispano-portuguesa se ha ido diluyendo al menos parcialmente en el marco de la integración europea, precisamente en un tiempo donde las Comunidades Autónomas de Galicia y Castilla y León asumían atribuciones, y consolidaban su autogobierno y sus competencias legislativas.

A pesar de la importancia alcanzada por los procesos de territorialización, si abordamos el análisis de las dinámicas demográficas y urbanizadoras, nos encontramos con un comportamiento muy similar en las tres realidades analizadas: las áreas metropolitanas y ciudadanas concentran cada vez más efectivos y potencialidad económica, comienzan a conformar auténticos ejes de desarrollo frente a las comarcas rurales aquejadas de decrecimiento y atonía productiva. Estos procesos serán el objeto del segundo apartado que individualizamos y, a este respecto, cabe señalar que Galicia y el Norte de Portugal se han beneficiado del desarrollo conjunto de un gran eje de urbanización que se extiende desde Ferrol-A Coruña hasta el área metropolitana de Porto, la auténtica espina dorsal de ambos territorios, frente a las dinámicas de despoblación constatables de Oeste a Este, esto es, entre Galicia y Portugal y el Oeste castellano-leonés (LOIS, 2004; PAZOS, 2005; LOIS y PIÑEIRA, 2010).

En tercer lugar, nos ocuparemos de la importancia explicativa que han alcanzado los sistemas de comunicaciones, la movilidad y la conectividad interregional del ámbito de estudio. Nos interesará comprobar si es posible referirse a la conformación futura de uno o varios sistemas espaciales autónomos de domi- 
nante ciudadana, o si el cuadrante Noroeste Ibérico sigue acusando una fuerte dependencia de los grandes centros metropolitanos de España y Portugal (Madrid, Barcelona y Lisboa).

El cuarto epígrafe tratará de conocer los intercambios económicos entre los territorios considerados, sus contrastes espaciales y su evolución reciente. En este análisis, nos encontraremos con ciertos problemas a la hora de unificar fuentes estadísticas diferentes, de manera particular las que se refieren al comercio bilateral y a las inversiones que se registran entre una Comunidad Autónoma española y una región portuguesa, y las que siguen los intercambios entre territorios españoles. No obstante, con las series disponibles esperamos conseguir una caracterización de los procesos de integración o indiferencia de los sistemas económicos de Galicia, Castilla y León, y el Norte de Portugal respecto a sus vecinos más próximos.

Por último, en las páginas finales se enumerarán las principales conclusiones de nuestro trabajo, sin olvidar las percepciones que las colectividades humanas de cada territorio han construido respecto a sus vecinas. En un plano más objetivable, también procuraremos verificar si los principales ejes de desarrollo de este cuadrante Noroeste ibérico presentan una disposición meridiana o siguen otras lógicas espaciales alternativas. Estas dos búsquedas tan diferenciadas de una tesis final de nuestro artículo se justifican como complementarias, ya que ambas nos permiten medir el grado de integración o de aislamiento respecto al vecino de los tres territorios analizados y desde puntos de vista contrastados.

\section{LA ORGANIZACIÓN POLÍTICO-ADMINISTRATIVA DEL CUA- DRANTE NOROCCIDENTAL IBÉRICO: RECONFIGURACIO- NES TERRITORIALES RECIENTES}

A partir de los mapas escolares u oficiales de amplia divulgación de España, Portugal y de la Península ibérica, siempre ha sido muy dificil acotar el cuadrante Noroccidental de Iberia, a diferencia del Suroriental o del Nororiental. Esto ha sido así por una razón muy simple: la frontera entre España y Portugal ha interrumpido en estas imágenes más o menos didácticas la continuidad de espacios que en principio presentaban enormes afinidades.

Durante mucho tiempo, e incluso entre los portugueses en la actualidad, se ha afirmado que la frontera política hispano-lusa era la más antigua de Europa, basándose para ello en el Tratado de Alcañices de 1297, a pesar de la muy dudosa realidad de esta afirmación. Es verdad que entre el Reino de Castilla y el de Portugal se trazó una línea de separación más o menos respetada, pero también es cierto que la misma no se estableció entre el Reino de Galicia y el de Portugal, que Olivença o incluso Barrancos son excepciones a este Tratado, que dió- 
cesis como la de Ciudad Rodrigo fueron secularmente transfronterizas, y así podríamos continuar (CABERO, 2002; LOIS, 2002).

De hecho, la noción sublimada de frontera se fue instalando en la conciencia colectiva coincidiendo con las dictaduras de Franco en España y de Salazar en Portugal, esto es, desde los años 1930 hasta los 1970. Una época en la que se generalizó la instrucción elemental a la población y donde en miles de escuelas se memorizaba un mapa idealizado de Estados-nación sin fisuras, en los que convenía no representar demasiados datos (o atributos) del territorio vecino.

La noción de frontera arraigada en el tiempo tuvo más significación en Portugal, donde la desconfianza a una anexión por parte de España todavía se mantenía (y produce algún fenómeno colateral en el presente) en la conciencia colectiva desde el siglo XVII. En España se recurría a cultivar un cierto menosprecio de lo luso, y las evidentes diferencias lingüísticas existentes en la raya castellano-portuguesa (que no habían sido tan pronunciadas a lo largo de la historia), contribuyeron a esta incomunicación bastante brusca. Por su parte, entre Galicia y Portugal no existían grandes barreras montañosas que separasen el territorio y las afinidades culturales entre el Sur de Pontevedra y Ourense y los espacios minhotos y trasmontanos fueron controladas por un sistema de guardia fronteriza y de limitación de las visitas autorizadas al país vecino, que sin embargo no impidió la generalización de prácticas de contrabando de todo tipo como expresión de una nueva época de relaciones en un contexto de impermeabilización de la raya (GODINHO, 1995).

Por lo tanto, el cuadrante Noroeste de la Península se fue construyendo de forma fragmentada a mediados del siglo XX, cuando el iberismo progresista y republicano de decenios anteriores había desaparecido, y en un período en el que los mapas políticos de España sólo reflejaban la división provincial y la existencia de regiones históricas (de contenido simbólico) (GARCÍA ÁLVAREZ, 2001), y los de Portugal apenas incluían las demarcaciones distritales, pues había que preservar la idea marcadamente unitaria y bien individualizada del territorio patrio.

La existencia de un cuadrante Noroccidental ibérico dividido en dos realidades estatales cerradas sobre si mismas, se fue diluyendo conforme el desarrollo económico del mismo introdujo elementos de modernización social (incremento de la movilidad, inicio de prácticas turísticas, auge de los desplazamientos con motivación comercial, etc.) y, sobre todo, se conjugó con procesos de democratización en los dos países ibéricos. En Portugal mediante un acontecimiento revolucionario iniciado en abril de 1974 y que, curiosamente, convertiría a este territorio en referente a seguir en el futuro por la España todavía dictatorial. 
Aunque los controles en la frontera se incrementaron, cada vez más personas se interesaban en conocer la experiencia de cambio político en el país vecino, con lo que de alguna forma las relaciones hispano-lusas comenzaron a intensificarse después de un largo período de adormecimiento. La posterior transición democrática española de 1975-78, culminaría con la aprobación de un texto constitucional que introduciría un modelo fuertemente descentralizado de gobierno y que, en consecuencia, pondría las bases de una nueva organización político-administrativa del territorio. En la misma se reconocía el derecho a la autonomía que, además de restituir el autogobierno local sin interferencias, abría el paso a las diferentes colectividades españolas para conformar un territorio autonómico a escala supraprovincial (AJA, 1999; GARCÍA ÁLVAREZ, 2002).

En el cuadrante Noroeste de España surgieron dos autonomías uniprovinciales (Asturias y Cantabria), en espacios con cierta singularidad, una tercera definida como nacionalidad histórica (Galicia, al haber aprobado un Estatuto de Autonomía en la II $^{\mathrm{a}}$ República y, también, al poseer una lengua propia) y la cuarta (Castilla y León), cuya creación no estuvo exenta de debates y polémicas (GARCÍA ÁlVAREZ, 2002), que integró a un conjunto dispar de provincias que se correspondían históricamente a la antigua Castilla-La Vieja junto al Reino de León. La democratización y modernización del aparato de Estado en España ha definido un mapa político cuasi federal, en el que las Comunidades Autónomas creadas han asumido un indudable protagonismo. Por su parte, en Portugal el período democrático ha preservado un carácter fuertemente unitario del territorio (con las excepciones insulares de Madeira y Açores), donde se han rechazado los intentos de regionalización, y en el que sólo los municipios dotados de amplias competencias, cierta base territorial y autonomía presupuestaria se han afirmado como autarquías.

Sin lugar a dudas, la situación insalvable de aislamiento dentro de las propias fronteras que caracterizó a las relaciones hispano-portuguesas durante decenios se ha superado por completo. No obstante, la nueva reconfiguración del mapa político-administrativo no es ni mucho menos simple. Así, la consolidación de regímenes democráticos y del Estado de derecho se ha traducido en la proliferación de normas legales, en la asunción dispar de competencias administrativas a distintas escalas, y en el reforzamiento de las identidades territoriales de base local y regional. Por lo tanto, es posible observar el incremento de los intercambios de todo tipo en un mapa mucho más abierto, si bien cada uno de los tres actores territoriales del Noroeste ibérico ha formulado sus propias políticas, estrategias y modelos de inserción espacial tanto a nivel interno como en relación a escalas más amplias.

Desde la perspectiva interautonómica (es decir, la que condiciona las relaciones entre Galicia y Castilla y León), resulta incuestionable que cada entidad ha 
desarrollado un modelo de organización interna diferenciado y de proyección hacia el exterior que prioriza unos ámbitos sobre otros. En Castilla y León la posición central de Valladolid se ha reafirmado, y los territorios de León y Zamora limítrofes con Galicia son interpretados como periféricos dentro de una nueva unidad política con débil cohesión interna.

A nivel oficial, los contactos y proyectos conjuntos con la comunidad gallega han sido numerosos, manteniéndose un alto grado de solidaridad entre los dos territorios, si bien ninguno de ellos considera a su vecino como un interlocutor preferente en términos económicos y de estrategias de desarrollo conjuntas: Galicia se ha fijado más en el Norte de Portugal con el que ha creado una Eurorregión, mientras que Castilla y León posee sus centros urbanos e industriales más dinámicos en las proximidades de Madrid y en el denominado Eje Irún-Aveiro (LÓPEZ TRIGAL, 1994; SÁNCHEZ HernÁNDEZ, 1998; MEIXIDE y De CASTRO, 2001).

Desde el punto de vista internacional, la frontera ha desaparecido, el tránsito de personas y mercancías se puede realizar con total libertad, aunque la Raya se mantenga en el imaginario de muchos habitantes de estos espacios, muy especialmente del lado portugués donde se ha perpetuado un deseo de independencia respecto a lo español y una percepción de amenaza (ahora económica, empresarial) por parte del vecino ibérico.

Las relaciones funcionan de manera excelente en el plano político y en numerosas demostraciones públicas de cooperación; esto, a pesar de que los matrimonios o la constitución de familias mixtas todavía no sean muy relevantes, y de que los progresos en el conocimiento de la lengua y la cultura del país limítrofe continúen siendo limitados. En cierta medida, el cuadrante Noroeste peninsular ha pasado de una separación rígida e insalvable entre los totalitarismos español y portugués a otra situación definida por su enorme complejidad donde regiones, municipios e incluso provincias/distritos o parroquias/freguesías cumplen unos papeles específicos en una organización espacial dialéctica y articulada a muy diversas escalas de decisión (y de actuación respecto al vecino).

Un hecho que sí se puede constatar para los últimos decenios son los resultados prácticos de la desaparición efectiva de la frontera con Portugal en el marco de la integración europea. Por una parte, se ha abierto un nuevo período de las relaciones hispano-lusas que insiste en la mejora de la comunicación bilateral. Se ha transmitido un mensaje de cooperación mutua y de aminoración de la desconfianza respecto al vecino. En un plano más material, las evidentes deficiencias de la red de comunicaciones terrestres entre ambos países (y en particular entre Castilla y León y Galicia, y la Región Norte de Portugal) se han ido superando. 
Desde los años 1980 se han construido nuevos puentes, se han ampliado carreteras, se han diseñado ejes viarios más funcionales $\mathrm{y}$, en definitiva, se ha tratado de facilitar el contacto y todo tipo de intercambios entre las comunidades fronterizas. Los progresos en accesibilidad y conectividad son notables. Por otra parte, los dos estados y la Unión Europea han trabajado de forma decidida en la implementación de planes transfronterizos de cooperación territorial para el desarrollo, en especial dentro de la iniciativa Interreg y mediante la dotación de proyectos LEADER y similares. Esto ha permitido generar solidaridades entre los municipios del Baixo/Alto Minho, formular propuestas sugerentes como la eurociudad Chaves/Verín o animar programas de desarrollo endógeno y de reducción del declive rural entre el Oeste zamorano y una serie de concelhos trasmontanos, entre muchos ejemplos (LÓPEZ TRIGAL, 1994; PARDELLAS, 2000; ALONSO y CAETANO, 2002; DomínGUEZ y VenADE, 2004).

Sin duda, el hábito del trabajo conjunto para lograr determinados objetivos de mejora territorial se ha generalizado entre alcaldes, concejales y directivos de asociaciones de todo tipo de los espacios rayanos, tanto a nivel local como provincial y regional. En tercer lugar, el clima de cooperación creado ha tenido su correlato en una multiplicación de las relaciones económicas y de los intercambios comerciales. El país vecino es percibido como un excelente y seguro mercado donde desarrollar la actividad, donde ampliar la capacidad de negocio. A este respecto, el desarrollo separado de España y Portugal en sus respectivos períodos dictatoriales justifica la existencia de estructuras productivas y laborales no coincidentes y, de este modo, explica que se aprovechen mejor las complementariedades económicas mutuas (mayor capacidad innovadora de las empresas españolas y sistemas más evolucionados de capitalización, mano de obra y suelo industrial menos costosos en los espacios portugueses, etc.).

Como fenómeno derivado de la dinámica que acabamos de comentar, ha sido perceptible una tendencia a la internacionalización de numerosas empresas de Castilla y León, Galicia y la Región Norte de Portugal. Un significado de internacionalización que puede variar desde la decisión de instalarse de forma efectiva y permanente en el país vecino hasta la simple práctica de vender o trabajar en un territorio del otro país cuando así se demanda. En todo caso, las prácticas económicas que no se podían desenvolver con anterioridad a mediados de los 1970 se han convertido en normales, en habituales, favoreciendo los más diversos contactos en estos últimos decenios.

En quinto lugar, y como consecuencia de lo anterior, se han ido consolidando flujos de movilidad cotidiana a través de la Raya cada vez más numerosos. Miles de gallegos y castellanos pasan a trabajar, a comprar o a disfrutar de su tiempo libre en el vecino Portugal todas las semanas, del mismo modo que cuadrillas de operarios, familias o ciudadanos portugueses solos vienen a Vigo, Ou- 
rense o Zamora de forma habitual por motivos laborales, por la necesidad de realizar compras o de conocer un nuevo destino turístico. Finalmente, esta reconfiguración territorial reciente a la que nos estamos refiriendo se basa también en una necesidad imperiosa de colaborar entre los dos Estados-nación ibéricos, entre las tres regiones del cuadrante Noroeste peninsular que analizamos y entre decenas de municipios/concelhos en el marco de un espacio europeo unido que se ha desplazado hacia el Este durante los últimos años, después de la conformación de una UE de 27 países, donde la Península Ibérica, Castilla y León, Galicia o el área metropolitana de Porto quedan cada vez en una situación más periférica, con riesgo creciente de perder el tren de la convergencia con los territorios más ricos del continente.

A lo largo de estas primeras páginas hemos retomado los argumentos de una serie de trabajos previos que realizamos en la década de los 1990 (Boletín de la AGE, 1997; LÓPEZ TRIGAL, LOIS y GUICHARD, 1997; LÓPEZ TRIGAL y GUICHARD, 2000; GUICHARD, LÓPEZ TRIGAL y MARROU, 2000; LOIS y PLAZA, 2003), sobre los cambios observados recientemente en los territorios de la Península Ibérica. La reflexión desarrollada ha sido teórica y evocadora de los procesos que han tenido lugar, como introducción general a una serie de análisis concretos que vamos a desarrollar a partir de este momento. La Geografía se preocupa por las dinámicas espaciales y por los procesos de regionalización, y como señalábamos al inicio el cuadrante Noroeste Ibérico constituye un laboratorio privilegiado para el estudio de territorios cambiantes, donde los escenarios de organización futuros se pueden intuir a partir de una serie de procesos significativos que se están produciendo en la actualidad.

\section{LA POLARIZACIÓN DEL CRECIMIENTO ECONÓMICO Y POBLACIONAL Y EL DECLIVE DE LAS ÁREAS RURALES}

Las ciudades han tenido siempre una importancia clave dentro del conjunto del territorio, pero es a partir del proceso de industrialización cuando se convierten en centros de desarrollo. La concentración de la población y de la riqueza hacen de ellas los centros vitales en todos los países (JACOBS, 1986). Es por ello que analizar cómo se articula el sistema urbano del Noroeste español será el objetivo principal de este apartado.

El crecimiento de las áreas urbanas suele asociarse al desarrollo de la actividad industrial. Autores como H. CAPEL (1981) afirman que la industria se ha convertido en un hecho urbano, y que paisaje industrial y urbano se encuentran íntimamente asociados. La razón de dicha asociación hay que buscarla en la percepción del empresario capitalista que ve en las concentraciones urbanas una serie de ventajas como son la existencia de economías de aglomeración, la reducción de costes al permitir la utilización de infraestructuras comunes y la pre- 
sencia de abundante mano de obra. Las décadas de 1950 y 1960 supusieron en España y Portugal el paso de una sociedad rural a una de carácter urbano.

Esta realidad estuvo acompañada de grandes transformaciones fruto de movimientos migratorios internos, crecimiento de las ciudades y concentración de la población en las mismas, que desencadenaron fuertes desequilibrios territoriales. No obstante, en 1950 sólo 18 ciudades españolas sobrepasaban los 100.000 habitantes, entre ellas A Coruña, Vigo y Valladolid (TERÁN, 1999). En el caso portugués eran Lisboa y Porto las que aglutinaban los principales movimientos migratorios procedentes del espacio rural, sobre todo de los distritos de Bragança y Vila Real que en esa década registraron pérdidas demográficas superiores al 15\% (SERRANO,1989).

Es a partir de los años 1970 cuando se empiezan a vislumbrar ciertas diferencias en el ritmo de crecimiento de las ciudades españolas y portuguesas. Mientras que en las primeras se observa el paso de la concentración a la descentralización demográfica hacia los municipios adyacentes (TERÁN, 1999) en Portugal, la expansión urbana continúa produciéndose en el interior de los municipios, en muchos de los cuales se registran incrementos de población superiores al $5 \%$ e incluso al $20 \%$. Un fenómeno que en parte obedece al gran tamaño de estos territorios y que se concentra en la franja noroccidental de la Región Norte, desde Coimbra, Aveiro, Braga y Viana do Castelo (SERrano, 1989).

Aún así, en 1970 la población censada como urbana en Portugal era tan sólo de un $22,6 \%$, porcentaje que si bien se incrementó hasta un 30,1\% en 1981, era débil en relación a otros países. Dato que, según afirma Serrano, hace pensar que el proceso de crecimiento de la población urbana portuguesa se encontraba por aquel entonces en una fase inicial. Sin embargo, el desarrollo industrial no fue el único factor que incidió en el proceso de urbanización del territorio. La consolidación de un sector terciario diversificado y con gran protagonismo en la generación de empleo, también jugó un papel destacado (TORRES y LOIS, 1995): se crearon servicios públicos, al tiempo que la actividad comercial y empresarial registró un fuerte impulso.

Actualmente, la actividad industrial del cuadrante noroccidental ibérico se concentra en la fachada atlántica de Galicia y Portugal, concretamente entre A Coruña y Ferrol al norte, Vigo-Rías Baixas, Guimaraes-Barcelos-Braga y el Gran Porto; Valladolid y Burgos son los principales polos industriales en Castilla y León, a los que se unen, entre otros, León, Ponferrada, Aranda de Duero, Miranda de Ebro

Las tendencias registradas los años 1960-1970, en los que se produjeron profundos cambios económicos y fuertes procesos de expansión urbana, determina- 
ron las bases para la organización del espacio del noroeste pensinsular, la cual todavía persiste en la actualidad y que pasamos a analizar a continuación.

Figura 1. Distribución de la población en el noroeste peninsular (2009)

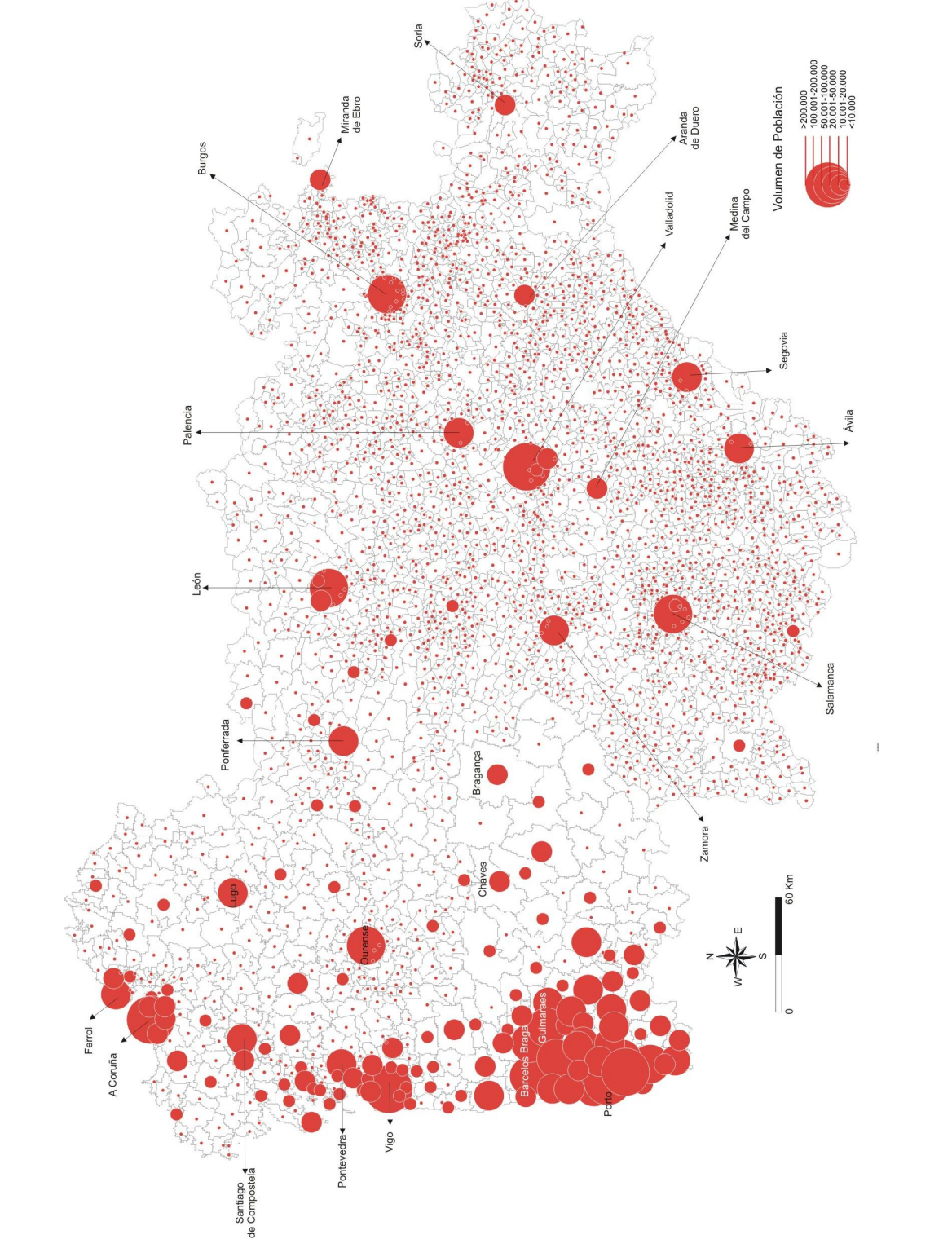

FUENTE: INE. 2009 
En primer lugar podemos establecer una clara diferenciación entre la realidad de la franja atlántica y la comunidad de Castilla y León. Mientras que en la primera nos encontramos una disposición longitudinal de las principales ciudades en torno al Eje Atlántico que se expande desde Ferrol hasta Porto, en Castilla y León nos encontramos con un sistema urbano poco vertebrado -debido a la falta de cohesión interna y la escasez de interrelaciones (JUNTA DE CASTILLA Y LEÓN, 2006)- con un nodo central, Valladolid, a partir del cual se distribuyen de forma radial las capitales de provincia. Esta modelo de organización interna diferenciado es fruto de que cada comunidad ha priorizado una estrategia de proyección al exterior focalizada hacia distintos ámbitos territoriales: como ya comentamos, mientras Galicia optó por estrechar lazos con el Norte de Portugal, Castilla y León se orientó hacia Madrid y el eje Irún-Aveiro.

Atendiendo a las cifras de población del Padrón de Población de 2009 podemos establecer una jerarquización de los principales núcleos urbanos del cuadrante noroccidental peninsular. No obstante, debemos detenernos en observar la disparidad existente en cuanto al tamaño de los municipios. Si el contraste es patente entre los municipios portugueses y gallegos por ser mucho más extensos los primeros y equivaler casi a una comarca gallega, el contraste todavía se hace más patente en relación a los municipios de Castilla y León, de reducida superficie, lo que sin duda redunda en el hecho de que en esta comunidad el $88,10 \%$ de los mismos tengan una población inferior a los 1.000 habitantes.

Destacan, en primer lugar, las ciudades que acogen más de 200.000 habitantes. A Coruña y Vigo en la comunidad gallega, Vila Nova de Gaia y Porto en la Región Norte y Valladolid en Castilla y León. Todos ellas aglomeraciones urbanas rectoras de un área de influencia, que en el caso de Porto destaca por su gran dimensión. Son centros dinámicos, en los que se concentra la actividad económica y entre los que existe una buena comunicación a través de la autopista del Atlántico (A9), la autovía de las rías Baixas (A52) y la A6.

Les siguen en importancia los municipios cuya población oscila entre los 50.000-200.000 habitantes. Entre ellos podemos diferenciar un conjunto de nodos urbanos primarios por su dimensión funcional y demográfica, y otros centros urbanos de carácter secundario que actúan orientados hacia sus ámbitos de influencia próximos, ofreciéndoles servicios y equipamientos de cierto nivel. Entre los primeros están las capitales de provincia del interior de Galicia (Ourense y Lugo) junto con Santiago de Compostela, capital autonómica y centro de equilibrio entre las aglomeraciones urbanas de A Coruña y Vigo; así como Burgos, Salamanca y León en Castilla y León.

En el caso portugués, entran dentro de esta clasificación los municipios de Gondomar, Matosinhos y Maia, en el distrito del Gran Porto; Guimaraes y Vila 
Nova de Famaliçao en el del Ave; Braga y Barcelos en el distrito de Cávado y Santa María da Feira en el de Entre Douro e Vouga. Sin embargo, el volumen demográfico que estos municipios acogen es mucho mayor en relación a los españoles. Si bien tan sólo Ourense, Burgos, Salamanca y León superan los 100.000 habitantes, en el caso portugués todos ellos pueden rebasar dicha cifra, dando como resultado la concentración de 1.229.750 personas en la parte occidental de la Región Norte. Entre los núcleos secundarios están Ferrol, Palencia, Ponferrada, Zamora, Ávila y Segovia, capitales de provincia y núcleos de industrialización endógena que actúan como polos de dinamización para su área de influencia más próxima.

En un tercer nivel se encuentran los núcleos cuya población oscila entre los 20.000-50.000 habitantes. Son los municipios que, o bien conforman la primera corona del área metropolitana de las principales ciudades, ejercen de cabeceras comarcales, o son lo que algunos autores definen espacios emergentes (PLAZA, 2000; ALONSO, 1997). Surgen en los últimos 20-25 años como nuevos territorios protagonistas en el proceso de crecimiento espacial, con áreas en las que se están desenvolviendo procesos productivos, de desarrollo territorial, de distinta naturaleza y proyección que los que caracterizaron el modelo centralizador de décadas anteriores En Galicia sería el caso de Narón, Oleiros, Carballo, Arteixo, Culleredo, Cambre en la zona del Golfo Ártabro; Ames, en los entornos de Santiago de Compostela y Vilargarcía de Arousa, Marín, A Estrada, Lalín, Redondela, Cangas y Ponteareas, en la mitad meridional gallega.

En el caso de Castilla y León, entrarían dentro de esta clasificación Soria, Miranda de Ebro y Aranda de Duero en la provincia de Burgos, San Andrés del Rabanedo en la de León y Laguna del Duero y Medina del Campo en Valladolid. Así mismo, se situarían los municipios del interior portugués de Chaves y Bragança, cuyos núcleos urbanos son de menor tamaño que sus homólogos gallegos (Lugo y Ourense), lo que sin duda obedece a que históricamente la división provincial en España tuvo mayor importancia que la división distrital en Portugal. A ello se une el hecho de que Lugo y Ourense, además de actuar como centros administrativos provinciales, han experimentado dinámicas no despreciables de industrialización y auge terciario (LOIS, 2007).

Finalmente, cabe mencionar una serie de núcleos cuyo contingente demográfico oscila entre los 10.000-20.000 individuos. Entre ellos podemos diferenciar: los que conforman la corona metropolitana de las principales urbes o que han visto aumentar su población a raíz de los procesos de metropolitanización; núcleos que polarizan grandes comarcas no solo en relación a su volumen demográfico, sino también porque en ellos se localizan los servicios públicos y la actividad comercial; y pequeñas entidades urbanas que durante los últimos años se 
han convertido en núcleos en los que se produce un nuevo modelo de organización económica y territorial.

Los cambios acontecidos en España y Portugal en el ámbito económico y social durante las últimas décadas han supuesto un conjunto de transformaciones en la organización del espacio, en el bienestar de las personas y en los modos de vida. Estos cambios podemos resumirlos en los siguientes items: el crecimiento económico y las transformaciones más llamativas de la estructura productiva; la consolidación del proceso de urbanización y la emergencia de una realidad metropolitana, de grandes archipiélagos urbanos interconectados que generan nuevas escalas de análisis de ámbito supramunicipal.

El resultado es el paso de una realidad urbana a una realidad metropolitana, reflejada en el crecimiento y la metamorfosis de los cinturones periurbanos (FIGURA 2), sobre todo en los casos en que si bien las ciudades rectoras no registraron crecimiento alguno en el periodo 1991-2009 (Ferrol, A Coruña, Porto, León, Valladolid y Salamanca), sí acusaron el cambio, los municipios de su periferia inmediata. El hecho de que las principales áreas urbanas se localicen en el Eje Atlántico, determina que la lógica del crecimiento metropolitano se concentre a lo largo del mismo.

Destaca el incremento demográfico registrado durante las dos últimas décadas en los municipios de Culleredo, Cambre Oleiros, Arteixo y Sada en torno a Coruña; Oroso, Teo y Ames (éste con un crecimiento del 169,5\%) en las proximidades de Santiago de Compostela; Ponteareas y Salceda de Miño en el área de influencia de Vigo; o Barbadás y A Porqueira en el caso de Ourense. Al igual que sucede en Galicia, el crecimiento de población en la Región Norte de Portugal se localiza principalmente en la vertiente atlántica, destacando el municipio de Maia (47,9\%) en el distrito de Porto, e en menor medida los de Valongo, Vila Nova da Gaia en el mismo distrito; Paços de Ferreira y Lousada en el de Támega; Santa $\mathrm{M}^{\mathrm{a}}$ da Feira en el de Entre o Douro e o Vouga; Braga en Cávado y Trofa en el distrito del Ave, todos ellos con un incremento que oscila entre el $20-30 \%$.

No obstante, este crecimiento podemos considerarlo moderado si lo comparamos con lo que sucede en Castilla y León, en donde los procesos de metropolitanización han provocado que numerosos municipios en torno las principales ciudades registren incrementos demográficos que superan el 100\%. Así mismo, es de destacar el hecho de que pequeños municipios tradicionalmente rurales con volúmenes demográficos en torno a 100 habitantes, dupliquen su población en los últimos años a raíz de la construcción de urbanizaciones (Quintanaortuño, Zaratán, Caracena, Pascualcorbo, Magaz de Cepeda, Moronta, etc.) lo que supone un gran impacto a nivel paisajístico. 
Figura 2. Crecimiento de Población registrado entre 1991 y 2009

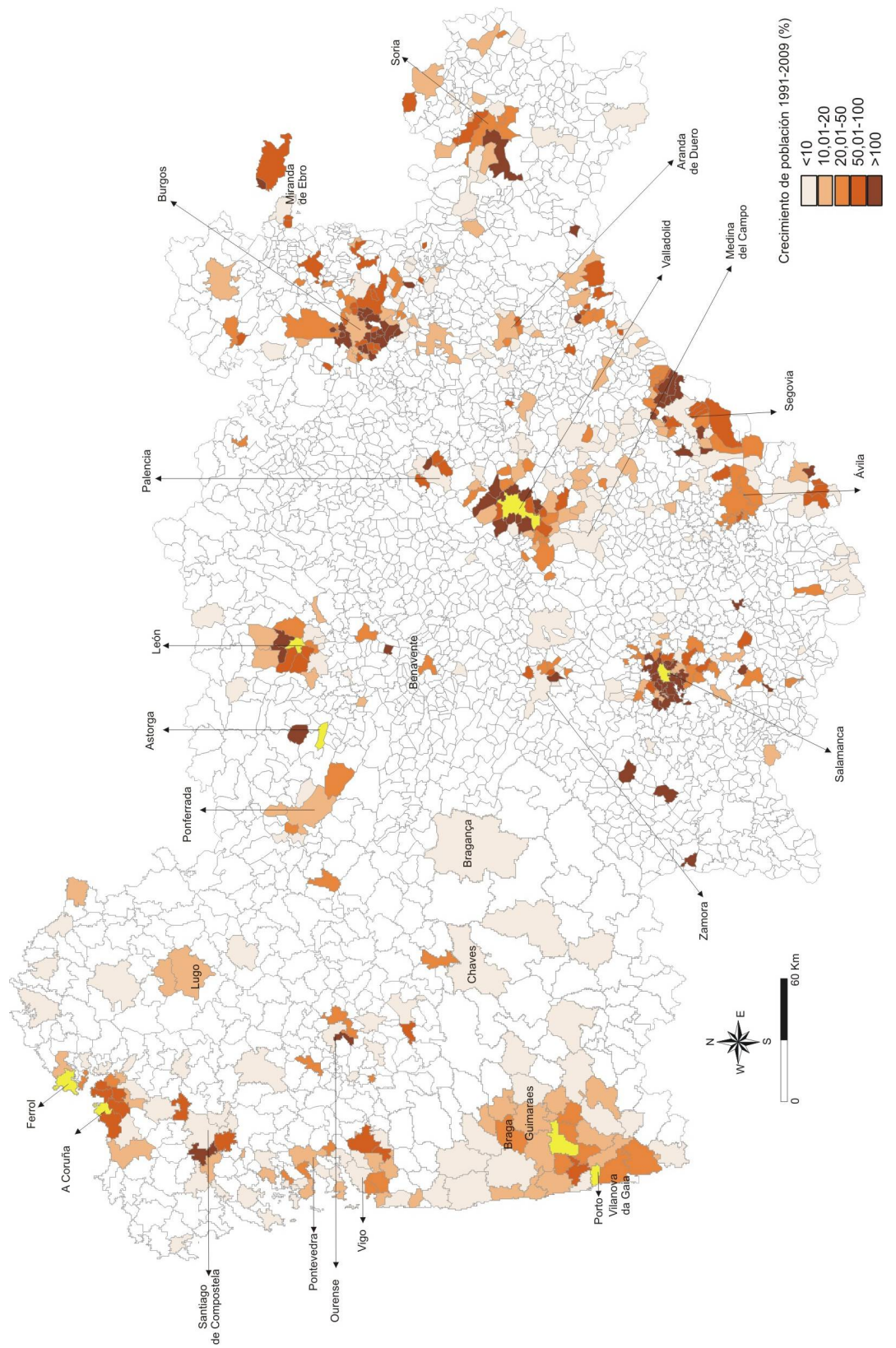

FUENTE: INE. 2009 
Figura 3. Urbanización en Quintanaortuño (Burgos)

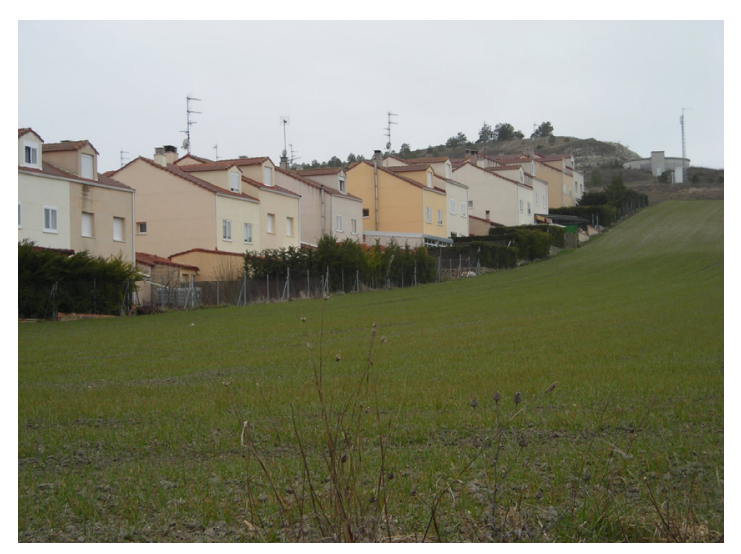

AUTOR: Miguel Pazos Otón (Marzo 2010)
Las consecuencias derivadas del proceso de metropolitanización podemos sintetizarlas en cuatro puntos:

El establecimiento de un nuevo orden territorial: municipios gallegos que en 1991 no alcanzaban los 20.000 habitantes, actualmente ascienden un peldaño en la jerarquía urbana al superar dicha

cifra, tal es el caso de Oleiros, Arteixo, Culleredo, Ames, Ponteareas cuya población oscila entre 33.000 y 23.000 individuos.

Cambios en el paisaje: grandes urbanizaciones se levantan en medio de entornos ruraFigura 4. Urbanización en Zaratán (Valladolid) les, sin que exista

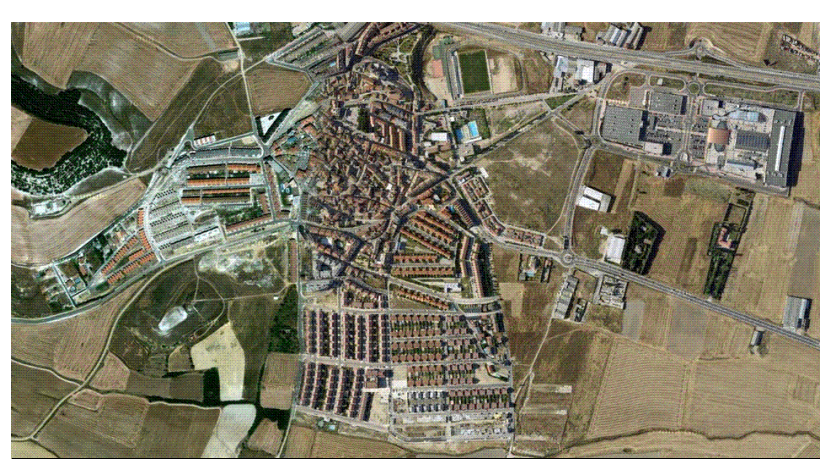

FUENTE: Google Maps (2010) una integración entre ambos espacios.

$\checkmark$ Incremento de los movimientos pendulares que exige una mejor accesibilidad con el núcleo rector.

Cambios en las densidades y estructuras demográficas: la llegada de población a esos municipios rejuvenece su estructura demográfica, al tiempo que determina el incremento de las densidades. (FIGURA 5). Con respecto a éstas, el hecho más destacado son las disimetrías litoral-interior en Galicia y, en menor medida, en el Norte de Portugal. El área metropolitana de Porto y sus vecinas de Braga y Guimaraes, y del sur (Entre Douro y Vouga) presentan valores muy elevados, superiores a $1.000 \mathrm{hab} / \mathrm{km}^{2}$, característicos de es- 
pacios urbanizados; unos valores que en Galicia se limitan a los núcleos rectores de Vigo y A Coruña. En cuanto a las áreas de interior, predominan las bajas densidades. Las ciudades albergan un contingente demográfico mucho menor que las del litoral, y numerosos pueblos se han visto afectados por graves procesos de despoblamiento. En todo caso, llama la atención las bajas densidades alcanzadas en la Comunidad de Castilla y León en la que un $37,7 \%$ de los municipios registran densidades inferiores a $10 \mathrm{hab} / \mathrm{km}^{2}$. Por el contrario, destacan los valores registrados en León, Salamanca y Burgos (con más de $1.000 \mathrm{hab} / \mathrm{km}^{2}$ ), los cinturones periurbanos de las mismas y capitales de provincia.

En definitiva, el cuadrante noroccidental peninsular se caracteriza por tener una ordenación territorial contrastada:

$\checkmark$ Frente un desarrollo urbano de carácter continuo a lo largo del Eje Atlántico en el que se concentra la población y la actividad económica; en Castilla y León prevalece un sistema urbano vertebrado de forma diferente, configurado por una red de pequeños asentamientos (5.845 núcleos) distribuidos con relativa homogeneidad por el territorio regional (SANTOS y PEIRET, 2001); y un escaso número de núcleos urbanos. Una ordenación que es fruto de la congelación de las estructuras territoriales ligadas a un sistema económicamente agrario y una escasa diversificación económica (DOT de la Junta de Catilla y León, 2000). No obstante, se perfilan situaciones que apuntan hacia nuevas formas de organización como es el corredor Palencia-Valladolid que ha crecido apoyado en la proximidad de las dos ciudades (tan sólo distan $52 \mathrm{~km}$ ), la extensión de las plantas industriales ligadas al sector del automóvil y las crecientes interrelaciones laborales y económicas. O el eje Irún-Aveiro, un corredor de transporte entre Ciudad Rodrigo, Salamanca, Valladolid, Palencia, Burgos y Miranda de Ebro, que ha asumido nuevos cometidos territoriales y ha concentrado nuevas actividades productivas, que permiten ejercer en la actualidad de espacio lineal de desarrollo, aunque tal y como demuestran los mapas precedentes, dista mucho de ser un eje de desarrollo urbano de la magnitud alcanzada por el Eje Atlántico (SÁNCHEZ HERNÁNDEZ, 1997).

Por otra parte, tanto en Galicia como Región Norte de Portugal, se observa un contraste litoral-interior. En el caso gallego, cinco de las siete ciudades principales se localizan a lo largo del Eje Atlántico, mientras que en el interior tan sólo destacan las capitales de provincia y numerosos núcleos terciarizados y con dotación de empresas que actúan como cabeceras de ámbito comarcal y que presentan claros rasgos urbanos. Por su parte, en la parte occidental de la Región Norte sobresale Porto y su 
área metropolitana que se prolonga hacia Guimaraes y Braga, frente al predominio de ciudades medias y pequeñas del interior.

Figura 5. Densidad de población de los municipios del espacio de estudio

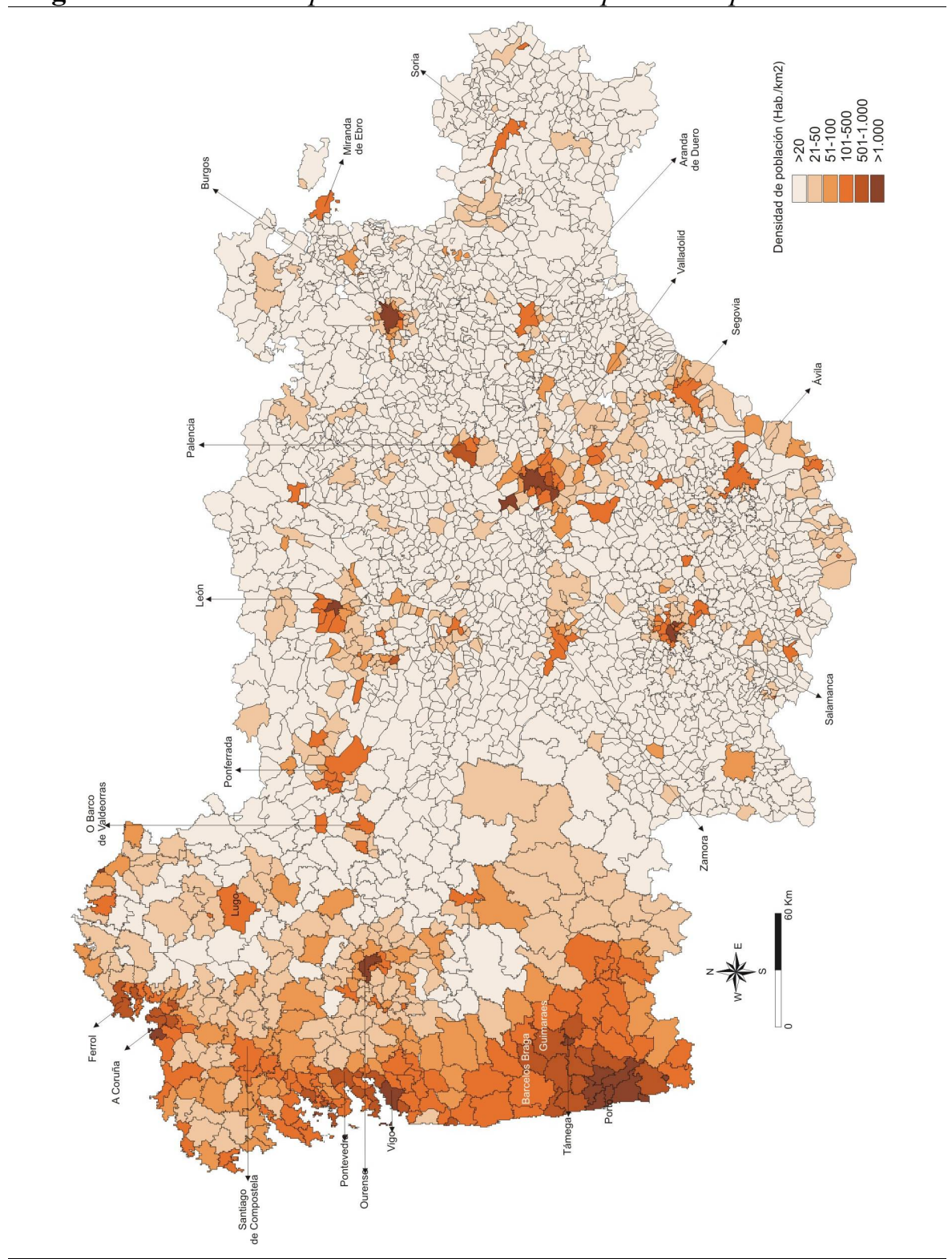

FUENTE: INE. 2009 
Frente un desarrollo urbano de carácter continuo a lo largo del Eje Atlántico en el que se concentra la población y la actividad económica; en Castilla y León prevalece un sistema urbano vertebrado de forma diferente, configurado por una red de pequeños asentamientos (5.845 núcleos) distribuidos con relativa homogeneidad por el territorio regional (SANTOS y PEIRET, 2001); y un escaso número de núcleos urbanos. Una ordenación que es fruto de la congelación de las estructuras territoriales ligadas a un sistema económicamente agrario y una escasa diversificación económica (DOT de la Junta de Catilla y León, 2000). No obstante, se perfilan situaciones que apuntan hacia nuevas formas de organización como es el corredor Palencia-Valladolid que ha crecido apoyado en la proximidad de las dos ciudades (tan sólo distan $52 \mathrm{~km}$ ), la extensión de las plantas industriales ligadas al sector del automóvil y las crecientes interrelaciones laborales y económicas. O el eje Irún-Aveiro, un corredor de transporte entre Ciudad Rodrigo, Salamanca, Valladolid, Palencia, Burgos y Miranda de Ebro, que ha asumido nuevos cometidos territoriales y ha concentrado nuevas actividades productivas, que permiten ejercer en la actualidad de espacio lineal de desarrollo, aunque tal y como demuestran los mapas precedentes, dista mucho de ser un eje de desarrollo urbano de la magnitud alcanzada por el Eje Atlántico (SÁNCHEZ HERNÁNDEZ, 1997).

$\checkmark$ Por otra parte, tanto en Galicia como Región Norte de Portugal, se observa un contraste litoral-interior. En el caso gallego, cinco de las siete ciudades principales se localizan a lo largo del Eje Atlántico, mientras que en el interior tan sólo destacan las capitales de provincia y numerosos núcleos terciarizados y con dotación de empresas que actúan como cabeceras de ámbito comarcal y que presentan claros rasgos urbanos. Por su parte, en la parte occidental de la Región Norte sobresale Porto y su área metropolitana que se prolonga hacia Guimaraes y Braga, frente al predominio de ciudades medias y pequeñas del interior.

También destacan los contrastes entre Castilla y León y la Región Norte de Portugal. En primer lugar porque, frente a la centralidad protagonizada por la ciudad de Porto; en Castilla y León prevalece un sistema polinuclear conformado por el núcleo rector de Valladolid y las nueve capitales de provincia. En segundo lugar, las diferencias se observan en el tamaño de los términos municipales, grandes en Portugal y muy pequeños en Castilla y León, factor que determina que frente a las grandes concentraciones demográficas alcanzados en los primeros, exista un nutrido número de territorios castellanos y leoneses con una población inferior a 1.000 habitantes. 


\section{LOS SISTEMAS DE COMUNICACIONES, LA CONECTIVIDAD Y LA MOVILIDAD INTERREGIONAL EN EL NOROESTE IBÉRICO}

El Noroeste de la Península Ibérica, el espacio que estamos analizando, se ha caracterizado siempre por su condición de periferia. La actual Eurorregión Galicia-Norte de Portugal estuvo fragmentada por una frontera prácticamente impermeable hasta el año 1986, en que España y Portugal ingresan en la UE. En este contexto de falta de articulación interna de la Eurorregión, tanto Galicia como el Norte de Portugal se constituyeron históricamente como periferias alejadas de los principales centros de decisión políticos de sus estados, Madrid y Lisboa, respectivamente.

La mitad norte de la Eurorregión, Galicia, ha sido a lo largo de su historia un ejemplo de espacio periférico y desconectado dentro de un estado centralizado y centralista. Además, la planificación del sistema general viario español adoptó desde el siglo XVIII un claro carácter radial. Dentro de estos esquemas, Galicia quedó conectada a finales de dicho siglo con la Meseta y con Madrid a través del Camino Real correspondiente (el remoto precedente de la actual A-6 o Autovía del Noroeste, Madrid-A Coruña). Es en esa lógica de comunicar la capital del Estado con las diferentes regiones litorales españolas (y en especial con los puertos) dentro de la cual hay que comprender la iniciativa de construcción de infraestructuras de transporte terrestres de altas prestaciones, de las que los Caminos Reales son precursores.

Sin embargo, y ya desde el XVIII, y en relación con otros espacios del Estado, las infraestructuras de transportes y comunicaciones siempre han ido llegando a Galicia con retraso. La falta de voluntad política, el débil peso económico de Galicia dentro de España, la distancia con los puertos de A Coruña y Vigo (más de $600 \mathrm{kms}$ ) y, por último, las dificultades orográficas de las Sierras Orientales gallegas son los principales factores que explican esta sistemática marginación (ALONSO y PAZOS, 2007).

El tradicional enfoque del "atraso" de Galicia (BEIRAS, 1972) ha concedido un importante papel explicativo a este hecho, que según este autor habría condicionado la formación de un mercado interno y las posibilidades de externalización de la economía gallega. La tardía llegada del ferrocarril a finales del siglo XIX, el Plan de Accesos a Galicia del tardofranquismo o las autovías del Noroeste y las Rías Baixas -ya en plena democracia- son buenos ejemplos de infraestructuras de transporte fundamentales que han ido llegando siempre más tarde al Noroeste de lo que sus homólogas lo han hecho a otros espacios de España. La tendencia continúa hoy en día, ya que algo semejante está sucediendo en la actualidad en relación con la llegada de la alta velocidad ferroviaria. 
Como ya hemos apuntado, la planificación y ejecución de nuevas infraestructuras de transporte siempre se ha encuadrado dentro de un modelo claramente radial. Madrid, kilómetro 0 de la red de carreteras, ha sido el centro indiscutible de la red viaria ya desde finales del siglo XVIII. Esta situación ha tenido continuidad hasta hoy en día, y no es posible comprender la vertebración del Noroeste Peninsular sin tener en cuenta este hecho.

De esta radialidad en el trazado deriva el hecho de que el corredor Madrid-A Coruña es el principal eje vertebrador del cuadrante Noroeste. Galicia, Asturias y el norte y oeste de Castilla y León utilizan total o parcialmente este eje para comunicarse con la Meseta y con la capital del Estado. En la actualidad, la localidad zamorana de Benavente aparece como uno de los grandes nodos de comunicaciones de todo el Noroeste Peninsular, donde convergen la A-6 (Autovía del Noroeste), la A-52 (Autovía de las Rías Baixas) y el eje AP-66 y A-66, que comunica Asturias con la Meseta (FigurA 6).

Por lo que se refiere a la integración entre Castilla y León y Galicia, podemos afirmar que ha sido siempre favorecida por el modelo centralista y radial imperante. El corredor Madrid-A Coruña, de interés para el conjunto del Estado, actúa también como eje de movilidad para la mitad norte de Galicia y Castilla y León, a través del puerto de Pedrafita do Cebreiro (con más de 1.000 metros de altitud). El sur de Galicia, por su parte, se comunica con la Meseta y con la comunidad castellano-leonesa a través de las Portillas del Padornelo y A Canda, por las que discurre la A-52.

Un tercer acceso a Galicia desde Castilla y León se realiza a través del valle del Sil. Constituye el acceso más factible desde el punto de vista topográfico, y ha sido la principal puerta de entrada a Galicia tradicional hasta la construcción del Camino Real entre Madrid y A Coruña. La facilidad para la movilidad entre la comarca gallega de Valdeorras y la comarca leonesa de El Bierzo ha configurado un espacio de proximidad e intercambio a caballo entre las dos comunidades autónomas. Esta tendencia histórica a la integración funcional de ambas comarcas se ha acentuado en la actualidad, debido a las mejoras en las infraestructuras de transporte. En un espacio periférico en relación con las capitales provinciales correspondientes (Ourense y León), Ponferrada emerge como un importante centro comercial y de servicios, que extiende su área de influencia incluso al sur de la provincia de Lugo. La próxima construcción de la autovía A-76 entre Ponferrada y Ourense favorecerá aún más la integración funcional de todo este espacio compartido por las dos omunidades autónomas.

Una lógica diferente ha seguido la comunicación entre Galicia y el Norte de Portugal. El hecho de pertenecer ambas unidades territoriales a sendos Estados independientes, y de ser las dos espacios "no centrales" en sus respectivos Esta- 
dos, ha jugado en contra de la integración transfronteriza a lo largo de la historia. La accesibilidad entre Galicia y el Norte de Portugal ha sido tradicionalmente deficiente, y no sólo por la debilidad de las infraestructuras transfronterizas, sino por los obstáculos y trámites necesarios para franquear la línea de frontera, que retrasaban de una forma muy notable el tiempo de desplazamiento.

Figura 6. Red viaria principal en el espacio de estudio

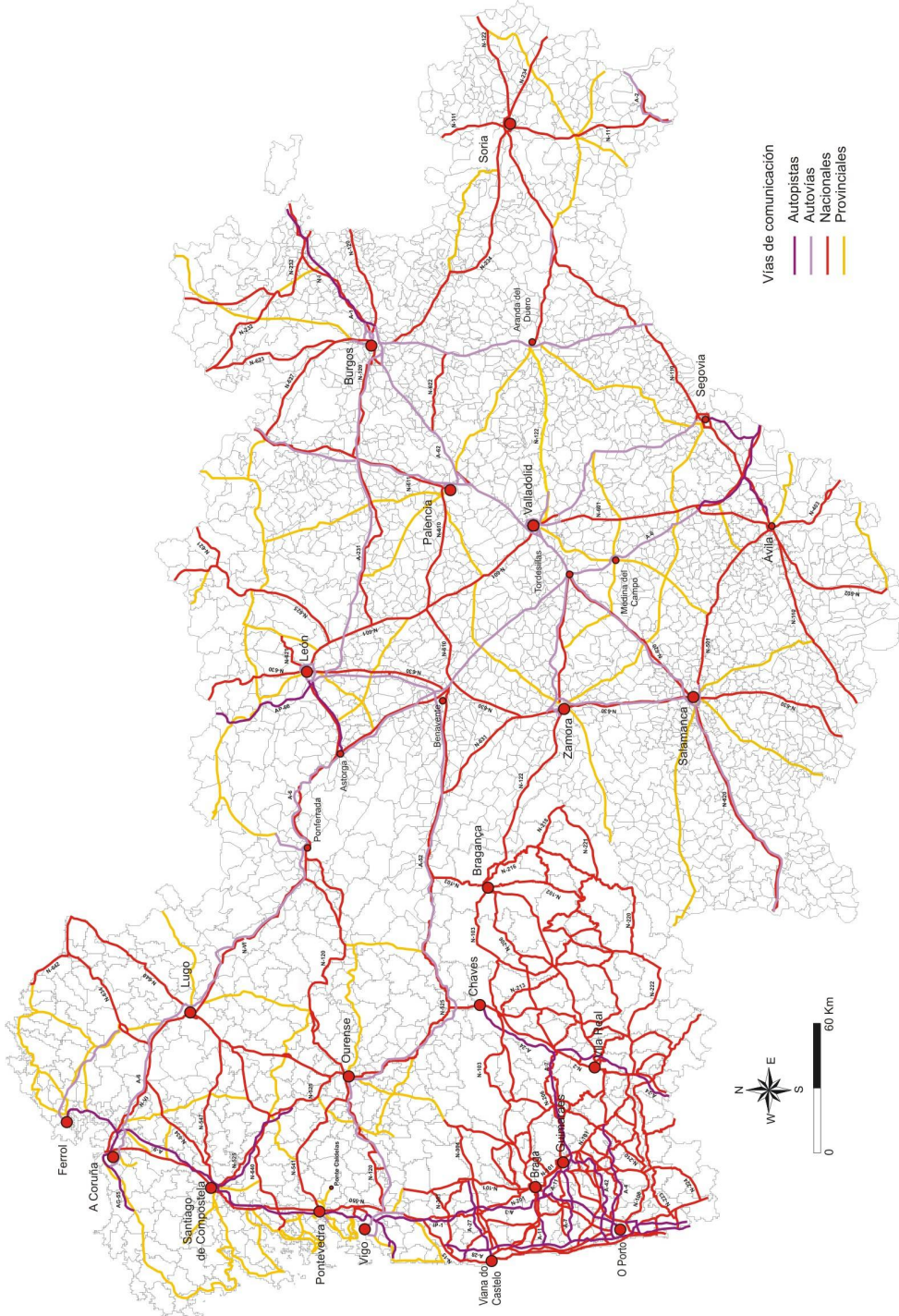

FUENTE: ANTE a partir de red de mapas de carreteras oficiales de España y Portugal 
Sin embargo, el ingreso de España y Portugal en la Unión Europea (1986) supuso un cambio total de escenario, al permitirse la libre circulación de personas y mercancías a uno y otro lado de la raya. La desaparición práctica de la frontera y la libertad de circulación hizo posible el surgimiento del concepto de "Eje Atlántico gallego-portugués". Se trata de un espacio de desarrollo axial marcado por la fortaleza de la red urbana (Ferrol, A Coruña, Santiago, Pontevedra y Vigo en Galicia; Viana do Castelo, Braga, Barcelos, Guimaraes y la aglomeración del Gran Porto en el Norte de Portugal) y por el dinamismo socioeconómico, que de facto constituye una unidad funcional cada vez más importante en el Noroeste Peninsular y en la fachada atlántica peninsular.

La finalización de la Autopista del Atlántico (AP-9) en Galicia y de la A3 en Portugal supuso un espaldarazo a la consolidación del mencionado Eje. Al mismo tiempo, la UE dedicó una parte muy importante de sus fondos de cohesión al fomento de la integración entre regiones fronterizas. La Eurorregión Galicia-Norte de Portugal supo desde el primer momento situarse en un lugar privilegiado para captar fondos europeos y aplicarlos a la planificación y gestión del territorio y los servicios. El Eixo Atlántico del Noroeste Peninsular, un "lobby" o "club de ciudades" que agrupa a los núcleos urbanos más importantes de la Eurorregión, basa su existencia en el apoyo expreso de la Unión Europea, que contribuye a su sostenimiento económico e impulsa su labor estratégica.

En cuanto a las comunicaciones por ferrocarril, se repite de nuevo el modelo centralista y radial. Madrid fue también -desde el siglo XIX- el nodo a partir del cual se organizó la red ferroviaria española, pensada básicamente para comunicar la capital del Estado con los puertos y los dinámicos espacios costeros. La llegada del ferrocarril a A Coruña se produjo en 1883 (una fecha tardía) e hizo posible la vertebración ferroviaria de todo el cuadrante noroeste peninsular. La línea transcurría por Medina del Campo, León y Monforte de Lemos, ramal ferroviario desde donde después se construyó una prolongación hacia Vigo.

Esta primera línea ferroviaria, que aprovechaba el paso natural del valle del Sil, permitió un sustancial incremento en las posibilidades de interacción entre Galicia y Castilla y León, tanto en viajeros como en mercancías. Con posterioridad, en 1959, se inauguró una nueva línea, Madrid-Zamora-Ourense-Santiago, la llamada "Línea Directa a Galicia", que además de acortar el tiempo de desplazamiento entre Galicia y Madrid, supuso un notable incremento de la accesibilidad ferroviaria entre Galicia y Castilla y León. Estas dos líneas conforman en la actualidad los dos corredores ferroviarios entre las dos Comunidades Autónomas. 
Debido a su posición geográfica, Castilla y León es un territorio de paso, y no sólo entre Madrid y Galicia. Otro de los grandes corredores ibéricos es el denominado Eje Irún-Aveiro (SÁNCHEZ HERNÁNDEZ, 1997), con una gran personalidad y con carácter internacional (se denomina E-80), que escapa a la lógica radial imperante. Estamos ante un corredor que se ha ido consolidando a lo largo del tiempo como la salida natural del Norte de Portugal hacia la Europa continental. Es además el principal itinerario viario que conecta la segunda aglomeración urbana de Portugal y el primer núcleo industrial (Porto) directamente con Francia y el resto de Europa. Aunque Aveiro no pertenece a la Eurorregión, consideramos pertinente incluirlo en este análisis, ya que como decimos, el Eje Irún-Aveiro constituye la salida natural de los espacios más dinámicos del Norte portugués hacia Europa. Por lo tanto, es un corredor estratégico para la movilidad no sólo de personas sino también de mercancías. En territorio portugués, el Eje Irún-Aveiro incluye a las ciudades de Aveiro, Viseu y Guarda. La frontera luso-española está flanqueada por Vilar Formoso y Fuentes de Oñoro (provincia de Salamanca). Ya en Castilla y León, el eje enlaza Ciudad Rodrigo, Salamanca, Valladolid, Palencia, Burgos y Miranda de Ebro (ver Figura 6).

La importancia de este eje se aprecia en la prioridad que los Estados portugués y español han dado a su conversión en vía de alta capacidad. En el lado portugués, la autoestrada Aveiro-Vilar Formoso (A25); en la parte española, la Autovía de Castilla (A-62), entre Fuentes de Oñoro y Burgos, y la autovía A-1, entre Burgos y el límite con el País Vasco aseguran una óptima accesibilidad transversal, y favorecen la integración de Castilla y León con la Región Norte de Portugal.

Por lo que respecta al ferrocarril, el Eje Irún-Aveiro también es muy significativo, ya que cuenta con servicios internacionales que enlazan el Norte de Portugal con la frontera francesa (Hendaya) (ver FIGURA 7).

Las compañías ferroviarias RENFE y CP prestan un servicio combinado, tanto de viajeros como de mercancías. En un país tradicionalmente emigrante hacia la Europa continental como Portugal, este servicio ferroviario ha desempeñado un papel crucial. Dentro de estas coordenadas, Castilla y León se ha comportado como un espacio de paso entre la Región Norte de Portugal y Francia, teniendo en cuenta que las vinculaciones entre Castilla y León y la Región Norte son más bien escasas.

Por lo que se refiere a los flujos de movilidad, contamos con datos de intensidades medias diarias de vehículos a través de los diferentes pasos transfronterizos en el espacio que nos ocupa. Los datos se refieren, por lo tanto, a los sectores fronterizos gallego y castellano-leonés, y proceden del estudio realizado por el OTEP (OBSERVATORIO TRANSFRONTERIZO ESPAÑA-PORTUGAL) en el año 
2003. A pesar de la relativa antigüedad de los datos, son enormemente valiosos porque permiten conocer cómo se establecen las relaciones funcionales en la Raya. Por otra parte, considerando la dificultad de encontrar datos de movilidad en general, los investigadores se ven abocados a utilizar datos que no siempre están recientemente actualizados (esto sucede, por ejemplo, con los datos de movilidad obligada diaria que contiene el Censo de Habitantes del INE, referidos al año 2001, y a partir de los cuales se siguen produciendo investigaciones y análisis).

Figura 7. Intensidad Media Diaria de vehículos particulares en los tramos fronterizos gallego y castellano-leonés con Portugal

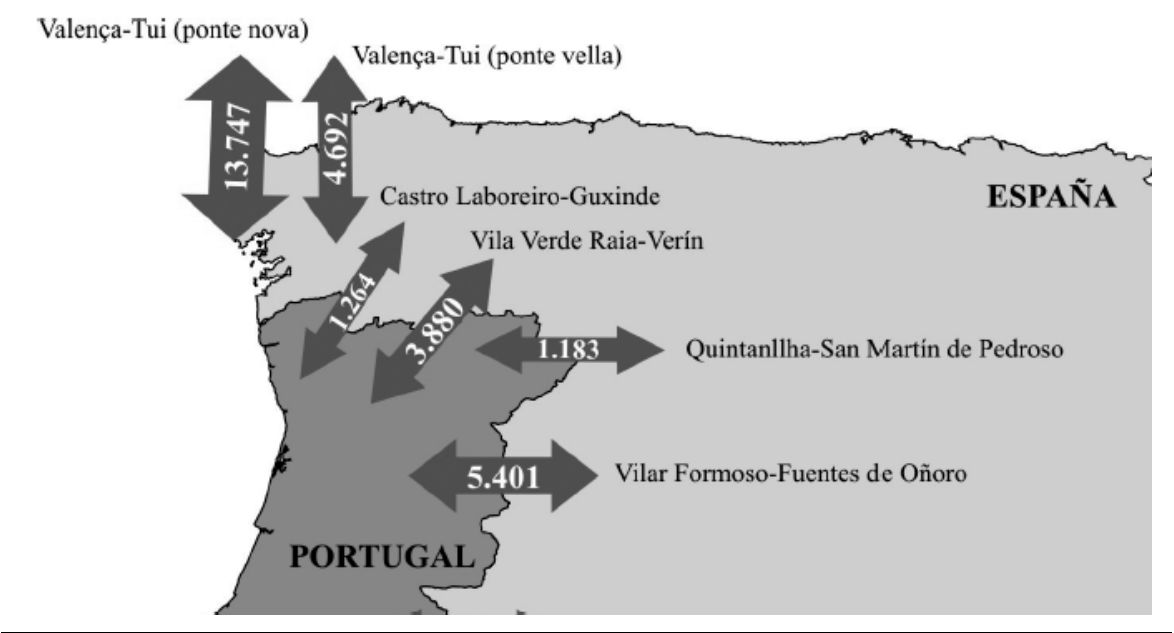

FUENTE: OTEP (2004)

La FIGURA 7 muestra la intensidad media diaria de vehículos de pasajeros en los sectores fronterizos gallego y castellano-leonés. Se puede observar claramente que el paso más importante es el de Tui-Valença do Minho, con más de 18.000 vehículos en total. Le sigue a mucha distancia el paso Vilar FormosoFuentes de Oñoro con 5.401 vehículos diarios.

El Eje Urbano Atlántico gallego-portugués aparece por lo tanto como un espacio fuertemente integrado, con una red urbana densa y diversificada, y unas altas densidades rurales y periurbanas que conforman un espacio axial en general muy desarrollado. Por el contrario, la ligazón entre Castilla y León y el Norte de Portugal es muchísimo más débil. Además, en la cifra total de vehículos hay que tener en cuenta que sin duda una parte importante se corresponde con tráfico internacional de paso, que se dirige hacia Francia y el resto de Europa. 
Los restantes pasos fronterizos son ya de carácter secundario, e inferiores a los 1.300 vehículos diarios en los dos casos (Castro Laboreiro-Guxinde y Quintanilha-San Martín de Pedroso). La excepción es el paso entre Vila Verde da Raia y Verín, con casi 4.000 vehículos. Es un valor elevado, sobre todo considerando que el ámbito de relación es básicamente comarcal y local. La integración creciente entre Verín y Chaves (que constituyen una eurociudad) es un factor explicativo fundamental.

Por su parte, si tomamos el tráfico medio diario de vehículos pesados de mercancías en el mismo espacio, observamos que ahora el paso principal es Vilar Formoso-Fuentes de Oñoro, con casi 2.000 vehículos diarios. El paso castellano-leonés duplica en número de vehículos al paso gallego, que no alcanza los 1.000 vehículos diarios.

El factor explicativo clave es, como ya hemos apuntado, el carácter internacional del Eje Irún-Aveiro, que atraviesa la frontera por Vilar Formoso y Fuentes de Oñoro, y se convierte en la vía de salida de buena parte de las exportaciones del Norte de Portugal hacia Europa. El significado de la circulación de mercancías a través de este corredor está muy relacionada con el hecho de que el área metropolitana de Porto es la segunda de Portugal por población y la primera del país en cuanto a su importancia como centro industrial.

\section{FLUJOS ECONÓMICOS: COMERCIO EXTERIOR E INVER- SIÓN EXTRANJERA DIRECTA EN GALICIA, CASTILLA Y LEÓN Y NORTE DE PORTUGAL}

En el Noroeste Peninsular, y más concretamente en el espacio conformado por Galicia, Castilla y León y el Norte de Portugal, resulta interesante observar las relaciones económicas y comerciales entre estos tres territorios. Al igual que los flujos de personas y mercancías expresan de forma bastante apropiada la interrelación entre territorios, también el análisis de diversos parámetros económicos (entre los que destaca la IED o Inversión Extranjera Directa) sirve para una aproximación a la comprensión de las dinámicas de relación en el espacio que estamos analizando. Un elemento que debemos tener en cuenta a la hora de realizar nuestros análisis es que los tres territorios pertenecen a dos Estados diferentes. Ello condiciona la homogeneidad de los datos de los cuales podemos disponer.

A la hora de seleccionar nuestras fuentes de estudio, además de los diferentes servicios estadísticos autonómicos (en Galicia y Castilla y León), hemos optado por emplear otras muy significativas como el informe "La internacionalización de la economía gallega". Se trata de un informe con periodicidad anual, dirigido por el Profesor Alberto Meixide Vecino, de la Universidade de Santiago de 
Compostela, que publica el Centro de Investigación Económica y Financiera de la Fundación Caixa Galicia.

La utilización de dicho informe ha resultado de utilidad para poder manejar datos ya depurados y tabulados por los autores, provenientes de la Agencia Tributaria Española (Ministerio de Economía) y del Registro de Inversiones del Ministerio de Industria, Turismo y Comercio. Dichos organismos, con los cuales hemos contactado, ofrecen directamente al investigador datos en bruto que requieren un tratamiento estadístico e informático complejo que excedía los límites del presente trabajo.

Aunque toman siempre como base territorial la Comunidad Autónoma gallega, los datos contenidos en dicha publicación resultan de interés porque en muchos casos se recogen informaciones económicas desglosadas para cada una de las Comunidades Autónomas del Estado español.

El problema surge, no obstante para trabajar con la Región Norte de Portugal como una unidad estadística, ya que fuera del territorio español los datos se refieren siempre a Estados y nunca a regiones. La situación no se resuelve fácilmente acudiendo a otras fuentes, considerando la falta de regionalización y el centralismo portugués, como ya hemos visto.

Para suplir estos condicionantes, los investigadores han desarrollado tradicionalmente estrategias que pasan casi siempre por la realización de entrevistas o encuestas con los principales agentes económicos. En este sentido, ha recibido una atención preferente la investigación de las relaciones económicas entre Galicia y el Norte de Portugal, dentro de los numerosos estudios y prospecciones en el seno de la Eurorregión Galicia-Norte de Portugal, un espacio que ha acelerado su integración desde 1986.

Merece la pena destacar sobre todo los trabajos de González-Portela Garrido, Lorenzo Paniagua y Cabanelas Lorenzo, que se han valido de la realización de una encuesta a 198 empresas de Galicia y el Norte de Portugal, que realizan negocios transfronterizos. En los cuestionarios se interrogaba a estos agentes económicos privilegiados sobre los motivos que les llevan a exportar, importar o fabricar en la región vecina.

También son interesantes las aportaciones de Rodríguez González, Pallas González y Fernández Leiceaga sobre la inversión extranjera directa en Galicia, un indicador que permite aproximarnos de manera muy apropiada a la realidad de la integración económica entre territorios.

Precisamente será la IED el principal indicador que tomaremos en nuestro análisis. La Inversión Extranjera, según el Fondo Monetario Internacional, es 
una inversión que debe llegar como mínimo al $10 \%$ del capital de la compañía sobre la que se realiza la inversión. Según Meixide y otros, "la IED refleja, por lo tanto, la intención última de obtener un interés de una entidad residente en una economía, por parte de una empresa que es residente en otra economía. Ese interés último debe implicar la existencia de una relación a largo plazo entre el inversor directo y la empresa en la que se ha realizado la inversión, con el objeto de obtener una influencia significativa en esta última".

A nivel metodológico, una última precisión que debemos realizar es la existencia de empresas con una fuerte implantación, impacto y generación de riqueza en estos tres territorios, pero que cuentan con sede y domicilio fiscal en las capitales de sus respectivos estados, Madrid y Lisboa. Este hecho es especialmente significativo en el caso gallego, en el cual en los últimos años se ha asistido al traslado de su sede a Madrid de importantes empresas como Unión Fenosa (hoy fusionada con Gas Natural) o FADESA (hoy Martinsa).

Comenzaremos nuestro análisis por las relaciones económicas entre Galicia y el Norte de Portugal. El ingreso de los dos Estados ibéricos en la Unión Europea supuso un cambio total de escenario no sólo en lo social y cultural, sino sobre todo en lo económico. De hecho, si se realiza un balance de los 24 años transcurridos desde 1986, la integración en el seno de la Eurorregión ha avanzado de forma desigual en diferentes aspectos. La integración social y cultural ha avanzado de manera desigual y lentamente; sin embargo, la integración económica ha sido rápida y muy importante.

Así, en el año 2008, según el Registro de Inversiones del Ministerio de Industria, Turismo y Comercio, Portugal era el segundo país inversor en Galicia, con 3.800 millones de euros de inversión, lo que representaba prácticamente el 17 $\%$ del total, como se puede ver en la TABLA 2.

Tabla 2: Principales países inversores en Galicia

\begin{tabular}{lrr}
\hline & Millones de euros & \% sobre el total \\
\hline 1. Francia & 8.704 & 35.8 \\
2. Portugal & 3.800 & 16.9 \\
3. México & 3.548 & 15.7 \\
4. Luxemburgo & 1.344 & 6.0 \\
5. Suiza & 1.331 & 5.8 \\
6. Suecia & 1.313 & 5.8 \\
7. Sudáfrica & 577 & 2.6 \\
8. USA & 504 & 2.2 \\
9. Noruega & 434 & 1.9 \\
Otros & 1.619 & 7.2 \\
\hline
\end{tabular}

FUENTE: MEIXIDE (2008) (coord.) a partir del Registro de Inversiones 
Los datos muestran que sólo otro vecino español, Francia, supera a Portugal en volumen de inversión. Además de la fortaleza de la economía francesa y de las transacciones asociadas a Citroën (empresa francesa que cuenta con una importante factoría de automóviles en Vigo), otro de los factores explicativos es el auténtico "bloqueo mental" entre España y Portugal antes del ingreso de los dos Estados en la Unión Europea. La ignorancia del vecino fue potenciada por ambas dictaduras y llevó a una política muy negativa para el cuadrante Noroeste de la Península Ibérica.

En este contexto, la peor parte fue para los espacios fronterizos, tanto en la raya gallego-portuguesa como castellano-leonesa. La Raya Húmeda del Miño o la Raya Seca Ourensana en Galicia, la tierra de Bragança, la Tierra de Alcañices, la comarca de Miranda do Douro o los Arribes del Duero se constituyeron en auténticos fondo-de-saco, lo que agudizó una situación ya de por sí difícil debido al carácter excéntrico y periférico en relación con los principales centros de actividad económica.

Si nos fijamos en la exportación de Galicia hacia Portugal, en el período 1993-2007, tal como señalan los mismos autores, Galicia se convirtió en la tercera comunidad española exportadora a Portugal. El volumen de inversión de multiplicó por 7 al final de dicho período, en relación con los niveles que presentaba al comienzo. Según los datos aportados por los autores anteriores, Galicia es la tercera comunidad autónoma española que más ha exportado a Portugal en el año 2007, con 2.321 millones de euros, tal como se puede observar en la TABLA 3.

Tabla 3: Comercio externo de las Comunidades Autónomas españolas con Portugal (millones de euros) referido a 2007

\begin{tabular}{lrr}
\hline & Exportaciones & Importaciones \\
\hline Andalucía & $1.359,8$ & 984,6 \\
Cataluña & $3.703,3$ & $1.432,4$ \\
Castilla y León & 933,2 & 558,8 \\
Madrid & $2.558,4$ & $1.558,3$ \\
Valencia & $1.089,9$ & 674,9 \\
Extremadura & 367,8 & 344,0 \\
Galicia & $2.321,7$ & $2.086,6$ \\
País Vasco & 901,7 & 281,3 \\
España & $15.660,9$ & $9.070,1$ \\
\hline
\end{tabular}

FUENTE: MEIXIDE (2008) (coord.) a partir del Registro de Inversiones

En efecto, los datos anteriores permiten apreciar que sólo Madrid y Cataluña (los dos motores económicos españoles) superan en volumen de exportación a Galicia. Conviene prestar atención en la tabla también al importante volumen de 
las exportaciones de Castilla y León a Portugal, en valores absolutos (933 millones de euros). Al igual que sucedía en el caso gallego con Citroën, aquí hay que tener en cuenta las transacciones asociadas a la factoría de automóviles Fasa-Renault, localizada en Valladolid y Palencia.

Sin embargo, desde el punto de vista relativo y observando las interrelaciones en el global del cuadrante del Noroeste de la Península Ibérica, la inversión de Galicia en el Norte de Portugal es más del doble de la de Castilla y León. Este hecho refleja la fortaleza de las relaciones meridianas N-S en el caso gallegoportugués, y la pervivencia del efecto frontera en el sector castellano-leonés. La potencia del Eje Urbano Atlántico y su continuidad al otro lado del río MiñoMinho contrasta con los espacios fronterizos a uno y otro lado de la raya zamorana y salmantina, débilmente ocupados desde el punto de vista demográfico y muy poco dinámicos económicamente.

Si atendemos a la naturaleza de las exportaciones e importaciones, cabe destacar la importancia de la implantación de industrias agroalimentarias que exportan a uno y otro lado de la raya. Ello se explica por homogeneidad de los patrones de consumo en este territorio, fuertemente cohesionado desde el punto de vista cultural.

Otro de los sectores de actividad económica en donde se ha avanzado en la internacionalización es el financiero. En las últimas décadas, los bancos y cajas de ahorros gallegos han abierto sucursales en los principales núcleos del Norte de Portugal y a la inversa. Además de la fuerte implantación de la Caixa Geral de Depósitos portuguesa en Galicia, cabe destacar la compra del gallego Banco Simeón por el portugués Banco Espírito Santo (BES), en un claro proceso de integración económica.

Otra de las claves explicativas que no debe pasar desapercibida se relaciona con la difusión de la actividad industrial de Vigo en buena parte de los municipios minhotos. La saturación del suelo industrial en el área metropolitana de Vigo y en el Baixo Miño gallego ha llevado a la mencionada difusión de buena parte de empresas auxiliares hacia el Norte de Portugal.

Los factores que explican este hecho son no sólo la disponibilidad de suelo, sino los grandes esfuerzos inversores a uno y otro lado de la Raya en dotar a este espacio de buenas infraestructuras, lo que ha convertido al Baixo Minho en un buen ejemplo de dinámico espacio económico transnacional. De hecho la futura Plataforma PLISAN (Plataforma Logística de Salvaterra-As Neves), ubicada a $35 \mathrm{kms}$ de Vigo y en plena frontera, se convertirá en un auténtico nodo de referencia que acelerará la integración económica y territorial a uno y otro lado del Miño-Minho. 
Tabla 4: Comercio exterior de Castilla y León con la Unión Europea en 2005

\begin{tabular}{|c|c|c|}
\hline & Millones de euros & $\%($ res. media UE) \\
\hline \multicolumn{3}{|l|}{ Importaciones } \\
\hline Francia & $4.774,5$ & 56,83 \\
\hline Alemania & 886,9 & 10,56 \\
\hline Italia & 666,64 & 7,93 \\
\hline Reino Unido & 603,92 & 7,19 \\
\hline Portugal & 507,73 & 6,04 \\
\hline \multicolumn{3}{|l|}{ Exportaciones } \\
\hline Francia & $3.023,49$ & 38,70 \\
\hline Alemania & 948,11 & 12,14 \\
\hline Italia & 842,29 & 10,78 \\
\hline Portugal & 834,82 & 10,69 \\
\hline Reino Unido & 799,15 & 10,23 \\
\hline
\end{tabular}

FUENTE: Elaborado por MARTíNEZ CAMPILLO y SIERRA FERNÁNDEZ (2009) a partir de Exportaciones FOB e Importaciones CIF del Departamento de Aduanas e Impuestos Especiales de la AEAT.

Retomando el análisis de las relaciones entre Castilla y León, contamos con los datos de comercio exterior de Castilla y León con la Unión Europea, referidos al año 2005. Los datos han sido elaborados por Sierra Fernández y Martínez Campillo a partir de exportaciones FOB e importaciones CIF del Departamento de Aduanas e Impuestos Especiales de la Agencia Tributaria española.

Como muestra la TABLA 4, el volumen de las importaciones realizadas desde Portugal es de 507 millones de euros, lo que supone el $6 \%$ del total. Pero además hay que tener en cuenta que el estado luso ocupa el quinto lugar en la lista, tras Francia, Alemania, Italia y Reino Unido, sus principales socios.

Algo semejante sucede con las exportaciones. Portugal es el cuarto cliente, con 834 millones de euros, lo que supone algo más del $10 \%$ del total, tras Francia, Alemania, Italia y Portugal. De nuevo los datos traslucen una importante integración económica en el caso castellano-leonés con Portugal, pero inferior a la que se registra para la Eurorregión Galicia-Norte de Portugal.

\section{CONCLUSIONES}

El cuadrante Noroeste constituye un espacio privilegiado para el análisis espacial de los cambios recientes en la Península Ibérica. Dejando al margen Asturias y Cantabria por razones operativas, a partir de finales de los años 1970 surgen tres entidades regionales (pertenecientes a dos estados: España y Portu- 
gal) que serán los protagonistas de nuestro análisis: Galicia, Castilla y León y el Norte de Portugal.

El siglo XX supuso en los dos Estados ibéricos el paso decidido de una sociedad rural a una sociedad urbana, fundamentalmente a partir de los años 1960. La población rural abandonó espacios agrarios con escasas perspectivas de futuro en una sociedad cada vez más industrializada y terciarizada.

Hasta el año 1986, esta realidad de cambio urbano y metropolitano se produjo dentro de los rígidos límites estatales. Pero España y Portugal ingresan en la UE en 1986, y el Tratado de Schengen consolida la libertad de circulación de personas y mercancías. El nuevo escenario significa una gran oportunidad para Galicia y el Norte de Portugal, con una gran afinidad cultural y lingüística. Beneficiados por la facilidad de comunicación física meridiana, la Eurorregión Galicia-Norte de Portugal se fue construyendo como una realidad cada vez más clara. Los responsables políticos de Galicia y el Norte de Portugal se esforzaron en "recuperar el tiempo perdido" y comenzaron a trabajar en red. La Comunidade de Trabalho Galiza-Norte de Portugal y, sobre todo el Eixo Atlántico do Noroeste Peninsular (un club de las ciudades más importantes) impulsaron la realización de estudios, investigaciones y planificación integrada. A pesar de que aún queda un largo camino por recorrer, es justo reconocer que Galicia y el Norte de Portugal están fuertemente integradas desde el punto de vista económico. El análisis de la Inversión Extranjera Directa, de las principales relaciones económicas y de las dinámicas vinculadas al suelo industrial refleja un panorama donde la frontera se encuentra prácticamente diluida. Diferente es la situación de la integración social y cultural, donde los Estados-Nación clásicos siguen pesando mucho, y resulta difícil superar la rígida frontera que tantos siglos lleva separando ambos territorios.

Por lo que respecta a Castilla y León y Portugal, desde 1986 se aprecia igualmente un incremento notable de la interacción. El análisis de los flujos de movilidad de personas y mercancías así lo refleja de forma clara. Sin embargo, todos los indicadores que hemos utilizado en este trabajo muestran que las relaciones son más débiles y más parciales que en el caso gallego.

Dos son los factores clave para explicar este hecho. Por una parte, la ausencia de afinidad cultural y lingüística entre Castilla y León y la Región Norte de Portugal. Esto contrasta mucho con la facilidad natural para la comunicación entre galegos y minhotos.

Por otra, la estructura de la red urbana es totalmente diferente. Galicia comparte con el Norte de Portugal una red urbana volcada hacia el litoral, y ambas presentan una clara continuidad natural gracias al Río Miño-Minho, que no se- 
para ya, sino que une. Por lo tanto, existen altas densidades de población e intensa actividad económica a uno y otro lado de la raya seca (no así de la raya húmeda). Podemos decir que el Norte de Portugal es la prolongación lógica del Eje Urbano Atlántico gallego.

Sin embargo, en el caso castellano-leonés o transmontano, la situación es muy diferente. Las comarcas fronterizas son espacios periféricos, en donde la creación de las autonomías (en España) y la emergencia del Gran Porto (en Portugal), ha reforzado su carácter marginal. Siempre han sido periféricas respecto a los principales centros de decisión de sus respectivos países, pero han aumentado aún más su excentricidad ahora debido a su alejamiento de Valladolid, Santiago de Compostela y Porto.

Al contrario que Galicia (proyectada hacia el Norte Portugués), Castilla y León ha mirado más hacia Madrid y el centro de la Península no sólo en aspectos sociales y culturales, sino también en la organización de su sistema de relaciones y económicas. Analizando los mismos parámetros que para el caso gallego, Castilla y León se encuentra mucho menos integrada con el Norte de Portugal, y ello teniendo en cuenta que el Eje internacional Irún-Aveiro puede distorsionar las cifras finales.

Para finalizar, debemos advertir que las relaciones entre Castilla y León y Galicia se han incrementado notablemente, aunque menos de lo que cabría esperar. El Estado autonómico configurado en 1978 permite posibilidades de cooperación nuevas, que se están llevando a cabo de manera oficial e institucional. Las grandes infraestructuras de transportes a nivel estatal han favorecido un incremento notable de la accesibilidad entre ambos territorios. Sin embargo, en este nuevo escenario donde se han definido nítidamente los tres territorios, parece que el incremento de las relaciones e integración entre Galicia y el Norte de Portugal representan la gran novedad, prueba de que las relaciones entre los territorios son cambiantes, al igual que la Geografía como disciplina.

\section{BIBLIOGRAFÍA Y DOCUMENTACIÓN}

AJA, E. (1999): El Estado Autonómico. Federalismo y hechos diferenciales. Madrid, Alianza Editorial.

Alonso Logroño, M. P. y PAzos Otón, M. (2007): «Implications of infrastructure policies for territorial development. The marginality of a peripheral region: Galicia (Spain)», en: JONES, G.; LEIMGRUBER, W. y NEL, E. (eds.): Issues of Geographical Marginality. Grahamstown, International Geographical Union and Rhodes University. CD-rom.

Alonso, J. L. y CAETANO, L. (eds.) (2002): Modelos de organización territorial en la raya central ibérica. Una visión de conjunto. Salamanca, Ediciones Universidad de Salamanca. 
BeIras Torrado, X. M. (1972): O atraso económico de Galicia. Vigo, Galaxia.

Boletín de la Asociación de Geógrafos Españoles, "Relaciones España-Portugal", nº 25, 1997.

Cabero Diéguez, V. (2002): Iberismo y Cooperación. Pasado y futuro de la Península Ibérica. Salamanca, Universidad de Salamanca, 2002.

CAPEL, H. (1981): Capitalismo y morfología urbana. Barcelona, Los Libros de la Frontera.

DomíngueZ, L. y VenADE, N. (2004): As Euro-Regiões e o futuro da Europa: o modelo da euro-região Galiza-Norte de Portugal. Porto, Ed. Eixo Atlântico do Noroeste Peninsular.

GARCÍA Álvarez, J. (2001): Territorio y nacionalismo. La construcción geográfica de la identidad gallega (1860-1936). Santiago de Compostela, Xunta de Galicia.

García Álvarez, J. (2002): Provincias, regiones y Comunidades Autónomas. La formación del mapa político de España. Madrid, Ed. Temas del Senado.

Godinho, P. (1995): «O contrabando como estrategia», A Trabe de Ouro, Tomo II, Ano VI. Abril-Maio, 209-222.

GUICHARD, F.; LÓPEZ TRIGAL, L. y MARROU, L. (2000): Itinerarios transfronterizos en la Península Ibérica. Zamora, Fundación Rei Afonso Henriques.

JACOBS, J. (1986): Las ciudades y la riqueza de las naciones. Barcelona, Ariel.

JunTA DE CATILla Y LEÓn (2000): Avance de Directrices de Ordenación del Territorio de Castilla y León. Salamanca, Taller de Ideas.

LOIS GonZÁLEZ, R. C. (2002): «As relações de Portugal com a Ibéria: uma olhada desde a Galiza», Lusotopie, n ${ }^{\circ}$ 10, 2002/2, 193-211.

LOIS GONZÁLEZ, R. C. (2004): «A model of Spanish-Portuguese urban growth: the atlantic axis», en Dela 21, Cities in Transition, 281-295.

LOIS GonZÁLEZ, R. C. (2007): Fronteras y análisis geográfico: la Raya gallegoportuguesa. Investigación presentada para la habilitación a Cátedra. Granada. (Inédito).

Lois GonZÁlez, R. C. y PIÑEIRA MANTIÑÁN, M. J. (2010): «A rede urbana e a rápida urbanización do territorio», en M. J. PIÑEIRA y X. M. SANTOS (eds.), Nova Xeografia de Galicia, Vigo, Ed. Xerais.

Lois GonzÁlez, R.C. y PlAZA GutiÉRreZ, J.I. (2003): «Development policies in the peripheral and marginal areas of the border between Spain and Portugal», en W. Leimgruber, R. MAyoral y C.-W. LeE (eds.), Policies and Strategies in Marginal Regions, Aldershot, Ashgate, págs. 114-130.

LÓPEZ TRIGAL, L. (coord.) (1994): Zamora. Un espacio de frontera, Zamora, Fundación Rei Afonso Henriques.

LÓPEZ TRIGAL, L. y GUICHARD, F. (coords.) (2000): La frontera hispano-portuguesa: nuevo espacio de atracción y cooperación. Zamora, Fundación Rei Afonso Henriques.

LÓPEZ TRIGAL, L.; LOIS GONZÁLEZ, R. C. y GUICHARD, F. (coords.) (1997): La articulación territorial de la raya hispano-portuguesa. Zamora, Fundación Rei Afonso Henriques.

Martínez CAmpillo, A. y Sierra Fernández, M. del P. (2009): La Unión Económica y Monetaria Europea en el proceso exportador de Castilla y León 1992-2007: un análisis de datos de panel. 
MeIXIDE, A. y DE CAStro, A. (coords.) (2001): Galicia e a Rexión Norte de Portugal: un espacio económico europeo. A Coruña, Fundación Caixa Galicia.

MEIXIDE, A. (coord.): La internacionalización de la economía gallega. A Coruña, Fundación Caixagalicia.

OBSERVATÓRIo TRANSFRONTEIRIÇO ESPANHA PORTUGAL (OTEP) (2004): Ministério das Obras Públicas, Transportes e Planeamento, Gabinete de Estudos e Planeamento (Portugal); Ministerio de Fomento, Secretaria General de Transportes (España), $3^{\circ}$ relatório. Lisboa y Madrid.

PARDEllas De BlÁs, X. (dir.) (2000): Plan de infraestructuras do Eixo Atlántico. Vigo, Servicio de Publicacións da Deputación de Pontevedra e Eixo Atlántico do Noroeste Peninsular.

Pazos Otón, M. (2005): Pontevedra Litoral. Hacia una ciudad continua. Pontevedra, Servicio de Publicacións da Deputación de Pontevedra.

PlaZA GUTIÉRREZ, J. I. (2000): «Ejes de crecimiento espacial y nuevos territorios de desarrollo en España: algunas reflexiones». Ería, 52, págs. 113-130.

Rodríguez GonzÁlez, X.A.; PAllas GonzÁlez, J. y Fernández LeiceagA, X. (2007): «La inversión extranjera directa en Galicia. Situación actual y estrategias de futuro». Revista Galega de Economía, vol. 16, 2.

SÁNCHEZ HERNÁNDEZ, J. L. (1994): «Evolución de la oferta y la demanda de transporte en el corredor viario Irún-Aveiro (E-80) entre 1975 y 1992». Boletín de la Asociación de Geógrafos Españoles, 19, págs. 45-66.

SÁNCHEZ HERNÁNDEZ, J. L. (1997): «El corredor viario Irún-Aveiro: hacia la formación de un eje de desarrollo», en Dinámica litoral-interior. Actas del XV Congreso de Geógrafos Españoles. Santiago de Compostela, vol. 2, págs. 951-960.

SÁNCHEZ HERNÁNDEZ, J. L. (1998): El eje Irún-Aveiro. Geografía de un eje de desarrollo. Salamanca, Caja Duero.

SAntos y Ganges, L. y Peiret CARrera, A. (2001): 174“A Articulación regional y comarcal en Castilla y León: las Directrices de Ordenación del Territorio175. Boletín de la Asociación de Geógrafos Españoles, 32, págs. 177-190.

SERRANO MARTÍNEZ, J. M. (1989): 174Notas sobre el sistema urbano y la organización del territorio de Portugal, Revistes Catalanes amb Acces Obert (RACO), vol. 23, $\mathrm{n}^{\circ}$ 1-2. En línea: < http://www.raco.cat/index.php/RevistaGeografia/article/viewFile/ $46040 / 56845>$.

TERÁN, F. de (1999): Historia del urbanismo en España III. Siglos XIX y XX. Madrid, Ed. Cátedra.

TORRES LunA, M. P. y LOIS GONZÁLEZ, R. (1995): «Claves para la interpretación del mundo urbano gallego». Anales de Geografía de la Universidad Complutense, 15, págs. 731-740. 